\title{
水利工程中堤坝裂缝及滑坡应急抢险方法
}

\author{
蒋秀杰 \\ 洮南市水利建筑工程队
}

DOI:10.32629/eep.v2i12.588

\begin{abstract}
[摘 要] 在水利工程中,堤坝是一种十分常见的工程项目,由于建筑工程的所用材料不同,堤坝也有很多种类,比如混凝土坝、千砌石坝、土石坝、 土坝等, 由于建筑成本及地理特点等因素, 土质堤坝相比其他种类的堤坝相对要多一些, 因为其施工容易, 成本较低, 许多地方可以就地取材进行 施工, 而且周期也较短, 但土质堤坝也相对容易出现裂缝、渗漏、背水滑塌、临水崩塌、漫溢和决口等险情。本文重点分析了堤坝的裂缝及滑坡 应急抢险方法,为堤坝的安全运行提供借鉴。
\end{abstract}

[关键词] 水利工程; 堤坝裂缝; 滑坡; 抢险

\section{1 堤坝裂缝及抢护}

\section{1 裂缝概述}

龟状裂缝。龟状裂缝多出现在土坝表面, 分布较均匀, 缝细而短, 对堤 坝危害较小。产生的原因主要是粘性土水分蒸发, 表面土体收缩, 故又称干 缩裂缝。填筑土料粘性愈大、含水量愈高, 干裂的可能性愈大; 横向裂缝。 横向裂缝的走向与堤坝轴线垂直或斜交, 常出现在堤坝顶部并伸入堤坝内 一定深度, 严重的可发展到堤坝坡, 甚至贯通上下游造成集中渗漏, 直接危 及堤坝的安全。主要是相邻堤坝段坝基产生较大的不均匀沉陷, 常发生于 堤坝合拢段, 堤坝体与交界部位施工分缝交界段以及坝基压缩变形大的坝 段等; 纵向裂缝。纵向裂缝的走向与堤坝轴线平行或接近平行, 多出现在 堤坝顶部或堤坝坡上部, 裂缝逐渐向坝体内部垂直延伸。它一般比横向裂 缝长, 若不及时处理, 雨水入侵后会造成大坝脱坡险情; 内部裂缝。产生内 部裂缝的原因和可能出现的部位有: 如在狭窄山谷压缩性大的地基上修建 土坝, 在坝体沉降过程中, 上部坝体重量通过剪力和拱的作用, 被传递到两 端山体和基岩中去, 而坝体下部沉陷, 有可能使坝体在某一平面上被拉开, 形成水平裂缝; 此外, 堤坝坝基或堤坝与建筑物接触处因产生不均匀的沉 陷而产生内部裂缝等。

\section{2 裂缝抢护}

针对裂缝所产生的原因进行重点分析, 并结合裂缝抢护措施进行合理 解决: 一是开挖回填。从某种意义上来讲, 在进行裂缝处理时尤其是在初 期阶段, 要选择合适的抢险措施防止裂缝的蔓延或是出现。尤其是在开挖 过程中必须灌入石灰水, 使其在可控范围之内。当裂缝较深时, 就要充分考 虑阶梯形槽坑与台阶之间的距离。在接口附近用于高水位的进行填充, 这

在制度保障方面, 各国都通过完善法律、政策引导和财政补贴来推动 生态建设。政府是生态建设的主导者, 必须通过制定科学的生态建设措施 和完善的污染惩罚制度; 制定相关的环境质量标准并要求相关主体严格遵 守; 鼓励和支持环保产业的发展; 使本国生态文明建设得以持续下去并最 终取得成效。生态建设必须以健全的法律为保障。法律是道德的底线, 是 国家意志。只有制定健全的环境保护法律体系, 提高公民的法制观念, 规范 全社会在人与自然关系面前的行为, 才会有有力遏制破坏生态的违法犯罪 的硬约束保障。

在建设主体方面, 各国均意识到仅靠政府是行不通的, 必须由政府一 厢情愿提高到全民主动参与。生态建设需要有全社会的支持。社会团体举 办各种环保活动, 在全社会形成环保风尚, 引导民众树立环保意识; 转变生 活方式和消费方式, 改变奢侈消费, 劣质消费, 盲目消费等习惯, 走可持续 发展道路。公司、企业、工厂要积极开发环保技术, 开发新能源、新材料,
样则可以降低裂缝处理时可能出现的枯水问题或是降水问题。二是充填灌 浆, 可采用灌浆法, 进行合理采挖回填, 一般情况下在进行较深裂缝的处理 时, 可以采取该项措施, 重点是必须确保顶部有两米及以上的开挖回填层, 以是有效防止浆液外喷, 在回填过程中可以采取重要措施, 进行浆液的浓 度是先稀后稠, 这样做的目的是为了更好地进行灌浆。

\section{2 渗漏及抢护}

2.1渗漏险情的分类

一是渗水险情。从某种意义上来讲堤坝分为干湿两部分, 对于水位 上面的部分可以称之为干堤坝, 水位下面的位置称之为湿堤坝。也可以 简单理解为是分界线, 从某种意义上来讲渗漏险情可以由很多种原因造 成。一般比较常见的则是渗水险情, 主要是由于堤身长期被其他物体所 侵蚀, 进而导致自身砂土层出现各种漏洞, 且堤面常年风吹雨淋、背水部 位又有陡坡会加大水流的冲击速度, 进而会造成险情的发生。二是管涌 险情。管涌险情的发生也是水利工程建设中比较常见的一种险情, 这种 险情的发生多半是因为透水性强, 降低了覆盖堤坝的临界坡度, 使得渗 水透过土体中的颗粒冲刷四周, 随着水土的流失使得通道内灌满了砂土, 长时间则会发生管涌险情的危险。三是流土险情。主要是渗水力在有压 力的情况下, 破坏了坝体的底部, 形成沙沸或是土体部位被冲刷走, 进而 发生的险情。这种险情的形成是贯穿整个坝体的, 且一旦发生所造成的 危险是极为严重的。

\section{2渗漏险情的抢护}

临水坡截渗: 抢护方法主要有: 土工膜截渗、抢堵漏洞进水口, 散抛 粘土截渗等方法。土工膜截渗: 当洞口较大或附近洞口较多, 可采用大面

尽量使用清洁能源和清洁材料, 废水废气废料经处理达标后排放。转变企 业生产观念, 变要我环保为我要环保。

\section{[参考文献]}

[1]间沛禄.资源型城市可持续发展的探索与实践 [D]. 中国地质大学 (北京),2012.

[2]冯禹丁.德国城市的和谐救赎,[J]商务周刊,2010,(13):52-56.

[3]朱菲菲,詹歆晔.新加坡水环境治理的经验借鉴 [ J ] . 上海节 能,2018,(04):259-262.

[4]张所续,石香江.浅谈新加坡水资源管理[J].西部资源,2007,(05):48-50.

[5]王碧栾,邱训平.新加坡水资源管理政策与实践 [J]. 水利水电快 报,2010,31(07):6-9+12.

[6]夏光.花园中的国度一一新加坡环境优先的发展策略.[J]环境与可 持续发展,2013,(03):114-115. 
积土工膜或蓬布, 沿堤坝迎水坡坡肩从上往下顺坡铺盖洞口, 然后抛压土 袋, 并抛填粘土, 形成前伐截渗。抢堵漏洞进水口: 漏洞险情处理最有效的 办法是及时准确堵塞进水口。散抛粘土截渗: 当堤坝临水坡漏洞口较多较 小, 范围又较大, 进水口难以找准或找不全时, 在粘土料充足的地方, 可沿 临水坡散抛粘土, 形成隔渗前伐。

背水坡反滤导渗: 反滤导渗沟。在背水坡坡脚渗水处, 开挖平行于堤 坝轴线的纵沟, 并与原有排水沟渠连通, 同时在出现渗水的顶部, 沿坡面开 挖坚沟。导渗沟内填砂石反滤料, 要分层填放, 应自坡脚向上分段施工, 随 挖随填, 不得停工待料。反滤料填好后, 顶面要铺编织袋、草袋或席片, 用 块石土方压实。在有条件的地方, 可用土工织物做导渗沟, 选用有效孔径的 土工布铺于沟的周围, 中间填透水料, 上部压盖草袋、席片、土袋等。在砂 石反滤料缺少的地方, 可利用麦秸、稻草等细料和柳枝、芦苇等粗料做导 渗沟。材料按下细上粗, 根向上、梢向下铺好, 上部用土袋、块石等压实。 所有导渗沟要与坡脚、排水沟连通。反滤层的做法是: 先将地面软泥、草 皮、砖石等杂物清除, 按反滤层的要求分层填铺砂石、土工织物、梢料等 反滤材料。反滤料和块石要适当延伸到坡脚外, 对堤身单薄, 渗水范围大, 又缺少砂石料的地方可利用麦秸、稻草等细料和柳枝、芦苇等粗料, 将反 滤层做成滤水后伐, 铺梢料要上下细, 中间粗, 梢料上部填土艻实, 铺一层 料, 填一层土, 直到达到计划后饯高度为止。

\section{3 滑坡及抢护}

\section{1 滑坡现象概述}

滑坡现象的产生也是由多种因素造成的, 尤其是在向坡度进行施工作 业时, 是极易因两端发展不均匀而出现滑坡, 但是起初阶段裂缝的发展速 度并不是很快, 而是会受到多种因素的影响。后期随着滑坡逐渐位移, 其导 致滑坡显现会越来越明显,一般有两种情况: 一是堤坝一起滑动; 二是堤 坝本身局部会随着滑坡进行移动, 且以两种不同的方式进行。但两种滑坡 一旦发生严重滑体现象都将会给水利工程建设带来较大的危险。

3. 2 滑坡抢修维护
一是在进行土坝防水滑坡的过程中首先必须降低水位, 充分保障坦 坝在足够的断水下可以进行裂缝上部的阻隔从而减少压力, 同时在进行 滑动坡体的过程中要尽量减少临时固脚情况, 这样极易导致滑坡的加 重。二是滤水滑坡。这里重点讲述的是在进行滑坡过程中由于渗透水的 系数偏小, 所以在进行排水作业过程中就会形成滑坡。这种情况下必须 采取导渗沟的方式进行填充, 然后再进行导渗法的加强, 用沙质进行合 理填充, 可以对其进行有效的加固。三是滤水后伐压载。如背水坡险情 严重, 可在其范围内全面抢筑导渗滤水后饯压载, 既能导出渗水、降低浸 润线, 又能加大堤坝断面, 可使险情趋于稳定。此法适用于断面单薄, 边 坡偏陡, 有滤水材料和取土较易处。四是打排桩压载固坡。当滑坡局限 于堤身且地基较坚实, 附近又有木料, 有些地方在紧急抢险时, 在滑坡坡 脚外打排桩, 加沙土包固坡脚, 防止滑坡发展, 待退水后再彻底处理。此 法内外坡滑坡均有采用。如有渗水, 同样要做好导渗, 以免沙土流失, 扩 大险情。五是临水截渗。在临水坡滑坡, 采用抢筑粘性土绒截渗。当背 水坡滑坡及渗水严重, 范围较广时除在背水坡抢护外, 如临水坡有条件 抢筑截渗土戗时,也可采用此法。

\section{4 结语}

水利工程建设过程中堤坝裂缝的出现和滑坡事故的发生, 都是比较常 见的一种事故。相关工作人员要第一时间分析发生事故的原因, 做到认真 分析, 合理解决。进而保证水利工程建设工作的有效实施, 并保证人们的生 命财产安全。

\section{[参考文献]}

[1]丛佩芹,吕玉霞.浅议堤坝常见裂缝及渗漏抢险技术[J].吉林农 业,2012(12):201

[2]廖少影.浅议堤坝常见裂缝的检查及抢护技术 [ J]. 吉林农 业,2014(03):56.

[3]王玉良.浅谈水利堤坝防渗技术[J].民营科技,2017(04):17. 